\title{
Ethylene-vinyl Alcohol Copolymer-based Embolic Agent
}

National Cancer Institute

\section{Source}

National Cancer Institute. Ethylene-vinyl Alcohol Copolymer-based Embolic Agent. NCI

Thesaurus. Code C128925.

A non-adhesive, non-absorbable, permanent liquid embolic agent comprised of ethylene vinyl alcohol (EVOH) copolymer dissolved in dimethyl sulfoxide (DMSO), and of micronized tantalum powder that can be used to occlude blood vessels. Upon administration of the $\mathrm{EVOH}$-based embolic agent, contact with fluids, such as blood, induces the solidification of EVOH into a sponge-like material. This causes occlusion of blood vessels and prevents blood flow to the treated area. 